\title{
UMA ANÁLISE DA EFICIÊNCIA DO PODER JUDICIÁRIO COM BASE NO PENSAMENTO DE DOUGLAS NORTH ${ }^{1}$
}

\author{
Marcia Carla Pereira Ribeiro ${ }^{2}$ \\ Rogério Rudiniki Neto ${ }^{3}$
}

\begin{abstract}
Resumo
O presente estudo busca problematizar a eficiência do Poder Judiciário, concebido como um serviço público. Para tanto, considera-se que apenas alterações legislativas não serão suficientes para reverter o quadro de ineficiência, pois o cenário é mais amplo, e fatores culturais devem ser considerados, o que revela a importância da análise institucional promovida por Douglas North. Utilizando-se de pesquisa bibliográfica e de dados secundários, o artigo parte do enquadramento do problema proposto para concluir que a eficiência do sistema de solução de conflitos judicias não depende unicamente da reforma da lei processual civil.
\end{abstract}

Palavras-chave: Eficiência; Poder Judiciário; Douglas North; Instituições; Cultura

\section{INTRODUÇÃO}

A proposta do artigo é de identificação do problema instalado a partir da constatação da finalidade a que se volta a jurisdição e sua relação com a noção de serviço público. Pretende analisar as deficiências do sistema posto, em razão de fatores que se relacionam a questões legislativas, operacionais e culturais.

Falar-se em fatores culturais, significa admitir que a mera modificação legislativa não é suficiente para a alteração do sistema, com vistas ao seu aprimoramento.

No Brasil, em razão de cultura enraizada de busca de apoio na legislação formal para mudanças institucionais, tem sido bastante comum a edição de modificações legislativas, especialmente no âmbito do processo civil.

O Novo Código de Processo Civil é mais uma demonstração da orientação predominante em nosso país. Opera-se habitualmente com redução de prazos e recursos e algumas mudanças conceituais, que não tem se mostrado suficientes para o real aperfeiçoamento do sistema.

\footnotetext{
${ }^{1}$ Artigo produzido no âmbito do projeto de produtividade da Fundação Araucária de Apoio ao Desenvolvimento Científico e Tecnológico do Paraná com o projeto Regulação de Riscos Empresariais no âmbito da atividade de Pesquisa \& Desenvolvimento para a Inovação (Chamada Pública 21/2012).

${ }^{2}$ Pós Doutora pela Escola de Direito da FGV/SP e pela Universidade de Lisboa. Professora titular de Direito Societário da PUCPR e professora associada da UFPR. E-mail: marcia.ribeiro@pucpr.br
} 
O trabalho optou pelo enquadramento do problema proposto no pensamento neoinstitucionalista, com base na teoria consagrada por North. Admite que no jogo de forças as reformas que se tenta implementar por meio de modificações das instituições formais pode sucumbir à força das instituições informais. Instituições informais que fortalecem um descompasso entre a busca pela eficiência e o sistema cultural relacionado à solução de conflitos.

A busca por um sistema eficiente exige que o paradigma da racionalidade seja acompanhado e, em parte substituído, pela análise de dados concretos.

\section{O PROBLEMA}

O principal escopo da jurisdição (tomada como aquela exercida pelo Poder Judiciário) é a justa composição da lide em um prazo adequado, devendo haver um emprego racional dos recursos alocados para o atingimento desse desiderato, levando-se em conta, especialmente, a gestão de massa dos processos. Nesses termos, conforme ensina Caponi (2011, p. 398-399), a jurisdição deixa de ser tida tão somente como uma função do Estado vocacionada à aplicação do direito ao caso concreto, para transmudar-se em "um serviço público destinado à composição das controvérsias segundo a Justiça”.

O conceito de serviço público é temporal e espacialmente delimitado. Corresponde às atividades às quais o Estado reclama para si a responsabilidade pela prestação (que poder ser feita de forma direta ou mediante concessão a terceiro), por considerar inadequado relegá-las integralmente à iniciativa privada. Desta feita, como tais atividades são perpassadas por especial interesse social, estão sujeitas ao princípio constitucional da eficiência.

Consigne-se, outrossim, que está consagrado na Constituição Federal o direito à duração razoável do processo ${ }^{4}$, noção intimamente ligada à eficiência da prestação jurisdicional.

Sobre a noção de eficiência, primeiramente é necessário diferenciá-la de outro conceito afim - o de eficácia. Conforme ensina Bittencourt (2011), a ideia de eficácia relaciona-se à aptidão, ou não, de determinada prática ou atividade atingir os objetos por ela pretendidos. Em outra toada, a eficiência preocupa-se com a economia no uso dos recursos tendo em vista os resultados (BITTENCOURT, 2011, p. 30). Dessa forma, pela ideia de eficiência, é possível que se considere a potencialidade de uma relação proporcionalmente inversa entre os resultados alcançados e os recursos despendidos em determinada atividade.

$\mathrm{Na}$ clássica visão de Vilfredo Pareto, a eficiência econômica era enxergada tão somente sob a ótica do bem-estar individual, quando se considerava como ótima toda situação em que a melhora de uma das partes levasse necessariamente a piora da situação da contraparte. Todavia, em sua acepção contemporânea, a eficiência

\footnotetext{
${ }^{3}$ Mestre em Direito Processual Civil pela UFPR. Pesquisador. Assessor TJPR. E-mail: rogerio.rudiniki@gmail.com

${ }^{4}$ CF, art. 5. ${ }^{\circ}$, inc. LXXVIII: "a todos, no âmbito judicial e administrativo, são assegurados a razoável duração do processo e os meios que garantam a celeridade de sua tramitação”.
} 
toma em conta os benefícios trazidos aos demais integrantes do corpo social, podendo, inclusive, ser utilizada como critério de elaboração e de monitoramento das leis - outrora estudadas pelos juristas tão somente sob a ótica da eficácia (BITTENCOURT, 2011, p. 31-36).

Retomando o tema da prestação jurisdicional, tem-se que no Brasil tornou-se lugar comum a afirmação de que ela é ineficiente.

Na lembrança de Gico Júnior (2012, p. 3), a garantia constitucional da inafastabilidade do controle jurisdicional torna o serviço público judicial um serviço comum, sujeito, portanto, à sobre-utilização. Outrossim, de acordo com o autor, (...) "a morosidade judicial desincentiva detentores de direitos a litigar e incentiva agentes interessados em postergar suas obrigações a utilizar o Judiciário, o que é um problema de seleção adversa, ainda mais trágico que a simples morosidade" (GICO JÚNIOR, 2012, p. 3).

Essa situação é paulatinamente agravada pela crescente disseminação da informação, que conscientiza as pessoas acerca dos seus direitos e lhes revela os meios que devem ser buscados para remediar os efeitos decorrentes de direitos que foram violados.

Ademais, no Brasil, há uma forte tendência de se subsidiar a litigância, o que, conforme Gico Júnior (2012, p. 36), é verificado em fatores como: (i) a criação dos Juizados Especiais, nos quais, via de regra, não é necessária a contratação de um advogado e não existe o pagamento de custas; (ii) a institucionalização da Defensoria Pública; (iii) o benefício da assistência judiciária gratuita, que desobriga que pessoas de baixa renda arquem com as custas processuais e com os horários advocatícios; (iv) o fato de que, mesmo nos processos nos quais não houve a concessão do benefício da assistência judiciária gratuita, o valor das custas processuais é nitidamente inferior ao custo social do processo. Como se vê, nesses casos, os custos do processo são redistribuídos entre o litigante e o contribuinte (GICO JUNIOR, 2012, p. 36).

A corroborar com tais afirmações, cita-se o relatório Justiça em números, divulgado pelo Conselho Nacional de Justiça no ano de 2014 (CONSELHO NACIONAL DE JUSTIÇA, 2014). Conforme aponta o estudo, atualmente tramitam no Poder Judiciário brasileiro 95,6 milhões de processos, sendo que 87,7 milhões então na primeira instância (42,6 milhões na fase de conhecimento e 43,1 milhões em execução) e 9,9 milhões nas outras instâncias). Ademais, a "taxa congestionamento" - que relaciona o número de casos encerrados com o número de casos novos e pendentes - no ano de 2013 atingiu a cifra de 91\%, ou seja, de cada 100 processos em trâmite naquele ano, apenas 9 foram concluídos. Para esquematizar esses dados, veja-se o seguinte gráfico constante do relatório em análise: 
Quadro 1: Movimentação Processual do Poder Judiciário em 2013

Casos novos $\square$ Processos baixados $\square$ Pendentes

\begin{tabular}{|c|c|c|c|}
\hline Tribunais Superiores & $\begin{array}{l}544.270 \\
496.486\end{array}$ & 534.237 & \\
\hline $2^{\circ} \mathrm{Grau}$ & $\begin{array}{r}3.270 .679 \\
3.260 .307 \\
\end{array}$ & 2.903 .723 & \\
\hline Turmas Recursais & $\begin{array}{l}993.835 \\
864.012 \\
\end{array}$ & 1.161 .250 & \\
\hline \multicolumn{4}{|c|}{ Conhecimento } \\
\hline Criminal & $\begin{array}{l}2.708 .985 \\
2.412 .211\end{array}$ & 4.913 .423 & \\
\hline $\begin{array}{r}14.005 .169 \\
14.474 .114\end{array}$ & & & 20.960 .409 \\
\hline $\begin{array}{ll}\text { Total Conhecimento } & \begin{array}{c}16.714 .154 \\
16.886 .325\end{array} \\
\end{array}$ & & & 25.873.832 \\
\hline
\end{tabular}

\section{Execução}

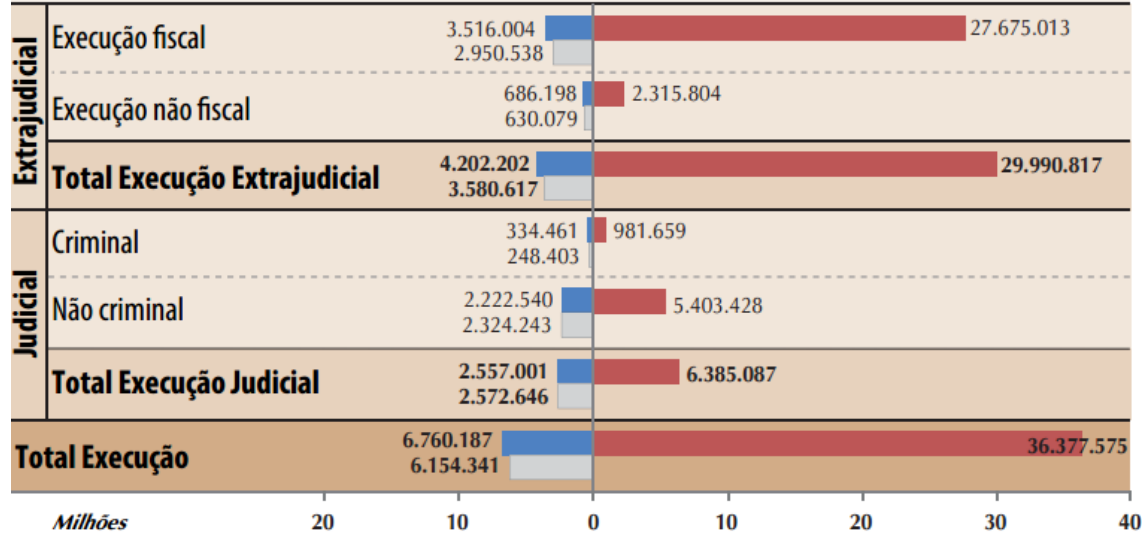

Gráfico 12 - Movimentação Processual do Poder Judiciário

Fonte: CONSELHO NACIONAL DE JUSTIÇA, 2014, p. 36

Atento a tais dados, o Novo Código de Processo Civil (NCPC), recentemente sancionado, surge com a promessa de contribuir com a redução da morosidade que há anos permeia o Poder Judiciário. Nesse sentido, a seguinte passagem da carta encaminhada ao Presidente do Senado Federal pela comissão de juristas responsável pelo anteprojeto:

A ideologia norteadora dos trabalhos da Comissão foi a de conferir maior celeridade à prestação da justiça, por isso que, à luz desse ideário maior, foram criados noveis institutos e abolidos outros que se revelaram ineficientes ao longo do tempo, mercê da inclusão de ônus financeiro aptos a desencorajar as aventuras judiciais que abarrotam as Cortes Judiciais do nosso país. A Comissão, atenta à sólida lição da doutrina de que sempre há bons materiais a serem aproveitados da legislação anterior, bem como firme na crença de que a tarefa não se realiza através do mimetismo que se compraz em apenas repetir erros de outrora, empenhou-se na criação de um novo código erigindo instrumentos capazes de reduzir o número de demandas e recursos que tramitam pelo Poder Judiciário (COMISSA O O DE JURISTAS NOVO CPC, 2009)

Porém, a simples promessa retórica de eficiência por si só em nada alterará o quadro vigente. A título exemplificativo, Caponi (2011, p. 398) lembra que o princípio da eficiência foi previsto no anteprojeto do novo código de processo civil italiano (elaborado por Proto Pisani). Em uma primeira abordagem, seria possível simplesmente enunciar tal princípio no texto legal, sem maiores detalhamentos, de modo que as formas de 
efetivação dessa promessa ficassem a cargo do trabalho dos juristas; contudo, tal atitude relevar-se-ia inócua. ${ }^{5}$ Destarte, Caponi (2011, p. 398) menciona o artigo do projeto italiano que contém as linhas interpretativas mestras do princípio da eficiência no processo civil, segundo esse dispositivo: "é assegurado um emprego proporcional dos recursos judiciários em relação ao escopo da justa composição da controvérsia em um prazo razoável, tendo em conta a necessidade de reservar recursos aos outros processos".

Sobre a gestão de processos e os recursos que devem ser a eles dirigidos, considerando a totalidade das demandas em curso, propõe Arenhart (2013, p. 47):

Avalia-se, antes, a atividade jurisdicional na sua relação entre o esforço estatal oferecido a um caso concreto e o todo de processos judiciais (existente ou potencial) que também tem direito ao mesmo esforço. Nessa linha, considerada a escassez dos recursos estatais, o grau de efetividade outorgado a um único processo deve ser pensado a partir da necessidade assegurar a eficiência do sistema judiciário como um todo. Por outras palavras, a alocação de recursos em um determinado processo deve ser ponderada com a possibilidade de se dispor desses meses recursos em todos os outros feitos judiciais (existentes ou potenciais). $\mathrm{O}$ serviço público "justiça" deve ser gerido à luz da igualdade e a otimização do que é prestado não pode olvidar a massa de processos existentes, nem os critérios para a administração mais adequada dos limitados recursos postos à disposição do ente público.

Em estudo sobre a eficiência do Poder Judiciário financiado pelo Banco Mundial e conduzido pelos professores Andrei Shleifer, Florêncio Lopes-de-Silanes, Rafael La Porta e Simon Djankov (DJANKOV, LA PORTA, LOPEZ-DE-SILANES E SHLEIFER, 2002), concluiu-se que o grau de regulação do processo em determinado ordenamento é inversamente proporcional à celeridade da Justiça. No estudo também foram considerados os seguintes pontos: (i) os aspectos de proteção ao réu nos diferentes sistemas; (ii) os incentivos aos advogados; (iii) a existência de prazos peremptórios para os juízes e os litigantes; (iv) a presença de métodos alternativos de solução de litígios, entre outros.

Nada obstante, não é possível acreditar que a eficiência ou ineficiência do sistema jurisdicional relacionese tão somente ao conteúdo de regras processuais. Não há dúvida que elas apresentam alguma importância, mas a questão é mais ampla. Retomando o multicitado pensamento de Caponi (2011, p. 399-400), pode-se afirmar que a eficiência dessa espécie de serviço público depende essencialmente de três fatores - o legislativo; o dos recursos (estrutural) e o cultural. Pelo primeiro fator, faz-se necessária a edição de leis modernas e capazes de dar conta das necessidades que dia a dia surgem no cotidiano da sociedade e do operador do direito. Pelo segundo, constata-se que a atividade jurisdicional não será eficiente caso os recursos financeiros e humanos à disposição do Judiciário e

\footnotetext{
${ }^{5}$ Em sentido similar, aduz José dos Santos Carvalho Filho sobre a eficiência da Administração Pública (consagrada no art. 37 da CF, pela EC 19/98): "Ou seja: quando se pode dizer que a atividade administrativa é eficiente ou não? Por outro lado, afirma-se ainda, de nada adianta a referência expressa na Constituição se não houver por parte da Administração a efetiva intenção de melhorar a gestão da coisa pública e dos interesses da sociedade. Com efeito, nenhum órgão público se tornará eficiente por ter sido a eficiência qualificada como princípio na Constituição. O que precisa mudar, isto sim, é a mentalidade dos governantes; o que precisa haver é a busca dos reais interesses da coletividade e o afastamento dos interesses pessoais dos administradores públicos. Somente assim se poderá falar em eficiência. O núcleo do princípio é a procura da produtividade e da economicidade e o que é vol.09, nº. 04, Rio de Janeiro, 2016. pp. 2025-2040 2029
} 
das atividades e ele conexas sejam demasiadamente escassos ou mal alocados. Já o último fator citado, o cultural, relaciona-se à necessária presença de operadores do direito (juízes, promotores, advogados, servidores etc.) que prezam pela lealdade e pela boa-fé e que são dotados de sólida formação, portanto, capazes de impulsionar e movimentar a máquina judiciária com a técnica adequada (CAPONI, 2011, p. 399-400).

Fixadas essas premissas, passa-se a abordar alguns desses fatores tendo como marco teórico o pensamento do economista norte-americano Douglas North.

\section{A ANÁLISE INSTITUCIONAL DE DOUGLAS NORTH}

Douglas North, vencedor do Prêmio Nobel de Economia em 1993, foi um economista americano conhecido por seus trabalhos na área da história econômica, tendo fundado juntamente com Ronald Coase e Oliver Williamson a "International Society for New Institucional Economics" (ISNIE).

Enquanto a Escola de Chicago parte do paradigma neoclássico, segundo o qual, em um contexto de escassez, os agentes são norteados pela racionalidade plena, para a Economia Institucional e para a Nova Economia Institucional (que adota as críticas tecidas pela primeira geração do movimento), a racionalidade humana e as condutas dela decorrentes são norteadas pelas instituições (AGUSTINHO e RIBEIRO, 2011, p. 121 e 125).

Conforme Agustinho e Ribeiro (2011, p. 124), as abordagens institucionais da análise econômica são guiadas pelas seguintes premissas:

(i) as instituições são importantes para a análise econômica; (ii) a determinação dessas instituições pode ser compreendida e explicada por meio do instrumental da teoria econômica; (iii) as instituições afetam o desempenho econômico de maneira sistemática e preditiva.

$\mathrm{Na}$ NEI os efeitos das instituições sobre as ações são consideradas e interferem nos resultados. A racionalidade é relativizada em seu papel absoluto na observação dos comportamentos e nas escolhas dos agentes econômicos. Da mesma forma, o pressuposto da concorrência perfeita é relativizado, já que o standard do mercado visto como ambiente no qual os agentes econômicos se habilitam a atuar de forma livre sofre a influência das instituições formais (as normas jurídicas) e informais (hábitos instalados na sociedade).

Daí a constatação de que políticas econômicas semelhantes produzam resultados diversos em diferentes ambientes institucionais. Por outro lado, firmam-se as hipóteses de que diante de um conflito entre normas formais impostas e normas socialmente consagradas, estas normalmente prevalecem sobre as demais.

mais importante, a exigência de reduzir os desperdícios de dinheiro público, o que impõe a execução dos serviços públicos com presteza, perfeição e rendimento funcional" (CARVALHO FILHO, 2014, p. 31). 
Contrariando a Escola de Chicago, que acredita que o Poder Judiciário é o melhor meio de solução de conflitos, neste aspecto a NEI valoriza os métodos privados, notadamente o contrato (AGUSTINHO e RIBEIRO, 2011, p. 125). Outrossim, cumpre ressaltar que a Nova Economia Institucional adota como pontos centrais de estudo a propriedade, o contrato e os custos de transação.

Sobre a propriedade, ainda que existam posicionamentos que a equiparam a um direito natural, cuja existência remonta à Alta Antiguidade, em verdade trata-se de um conceito relativo, que varia no tempo e no espaço (GROSSI, 2006, p. 26). A propriedade é um artifício criado pelo homem para resolver sua tormentosa relação com os bens. Sistemas jurídicos e sociais que operam com clareza na definição do direito de propriedade tendem a evitar conflitos e a otimizar os recursos produtivos, já que libera o agente/proprietário de sua tarefa de proteção de seus bens para que possa dedicar-se à produção. Os conceitos estão bastante consolidados no que se refere à propriedade corpórea e gera instigantes reflexões em relação à incorpórea, já que os limites dos direitos de exclusividade têm base puramente na definição normativa, pois os bens imateriais não sofrem a restrição inerente aos bens corpóreos, em sua generalidade, com relação ao uso excludente.

Por sua vez, o contrato, em sua acepção moderna, foi criado com o objetivo de possibilitar a circulação da propriedade, que se encontrava imobilizada no Medievo (ROPPO, 2009, p. 36-37). Os contratos instrumentalizam as trocas econômicas e admitem uma utilização que não encontra empecilhos na questão do grupo social a que pertence o agente. A atividade econômica é absolutamente dependente dos contratos, a ponto de ser possível o estudo da empresa por intermédio dos contratos relacionados ao exercício da atividade empresarial, como um feixe de contratos que possibilita a ação econômico-empresarial.

Já a noção de custos de transação surge em oposição aos modelos econômicos tradicionais, que tinham como pressuposto a absoluta racionalidade dos agentes, possuidores de todas as informações necessárias à tomada da melhor decisão (TOKARS, 2011, p. 89). Ocorre que, na prática, verifica-se justamente o contrário, os agentes não têm acesso às melhores informações, ou, ainda que tenham, muitas vezes são incapazes de processálas. Os custos de transação são os custos de negociação, associados às diversas etapas de um contrato. Custos anteriores à assinatura do contrato, como aquele de escolha do parceiro e de tomada de informações précontratuais, assim como custos posteriores, relacionados, por exemplo ao enforcement do que foi acordado. Se antes da Teoria dos Custos de Transação a ênfase dada pela economia era no sistema de preços, acreditando-se que a racionalidade dos agentes e o ambiente concorrencial agiriam de forma a estabelecer um ambiente de equilíbrio geral, a Nova Economia Institucional volta-se aos fatores que interferem na formação do ambiente.

Por fim, como já mencionado, os trabalhos de Douglas North ficaram caracterizados pela utilização da História Econômica. $\mathrm{O}$ autor faz uso da história das instituições como termômetro para análise dos motivos que fazem com que alguns países apresentem melhor desempenho econômico que outros (AGUSTINHO e RIBEIRO, 2011, p. 126). 


\section{O conceito de instituição para Douglas North}

Dentro do pensamento de Douglas North, as instituições são as regras do jogo da vida em sociedade. Moldam as formas de interação social e são fundamentais para a análise das mudanças percebidas no decorrer da história. Para North, as instituições englobam qualquer restrição criada para ditar a interação humana, podendo ser - como será desenvolvido adiante - formais ou informais (NORTH, 1990, p. 3-4).

Por ora, é necessário diferenciar as organizações das instituições. As organizações - assim como as instituições - criam estruturas para o desenvolvimento das relações humanas. Contudo, as instituições são anteriores às organizações, que se desenvolvem a partir de determinado quadro institucional. As organizações incluem corpos políticos, sociais, econômicos, educacionais, e, por conseguinte, o Poder Judiciário (objeto deste estudo) (NORTH, 1990, p. 5-6).

O principal papel desenvolvido pelas instituições é o de redução da incerteza, mediante a criação de estruturas estáveis - não necessariamente eficientes - para o desenvolvimento do jogo social (NORTH, 1990, p. $6)$.

Ato contínuo, verifica-se a existência de instituições de ordem formal e de ordem informal. As formais correspondem às regras oficiais, via de regra provenientes de uma fonte estatal, que regulam as relações humanas. Por outro lado, as instituições informais são materializadas nos costumes, nas tradições, nos códigos de conduta etc. (NORTH, 1990, p. 6).

É certo que as instituições formais podem ser alteradas de forma rápida, ou mesmo abrupta, por meio por exemplo - da promulgação de uma nova lei. Nada obstante, as instituições informais - que decorrem da repetição de práticas coletivas ao logo do tempo - tendem a ser de lenta alteração.

Em outra toada, a ideia de instituições informais pode ser associada com a noção de discurso que decorre do conjunto de práticas (repetidas de forma coletiva) peculiares a uma sociedade historicamente localizada. O discurso não é fechado, em verdade é um processo, que se mantém pela constante reprodução das práticas e ele ligadas; ou que se transforma pelo surgimento paulatino de novas práticas (ORLANDI, 2000, p. 32).

Sob esta óptica, ao analisar-se a história ocidental, percebe-se várias rupturas no discurso que tiveram como consequência o surgimento de experiências diversas. Exemplos nítidos de ruptura estão na transição do período Clássico para o Medievo, ou do Medievo para a Idade Moderna. Todavia, a mudança de um discurso dominante não é um processo demorado, a substituição das práticas reiteradas e a mudança da mentalidade coletiva podem levar séculos. 
Como já dito, para North, as instituições são criadas com o escopo de redução das incertezas que decorrem da disponibilidade de informações insuficientes e da consequente racionalidade limitada ${ }^{6}$ dos agentes. Em uma análise comportamental, $90 \%$ das nossas ações não demandam maiores reflexões, isso em razão da presença das chamadas instituições embutidas, que fazem com que não se precise pensar sobre os problemas antes de tomar uma decisão (NORTH, 1990, p. 22), pois nos comportamos de acordo com padrões de conduta socialmente aceitos e repetidos de forma coletiva durante longos períodos.

Porém, nem sempre as instituições (tanto as formais como as informais) são eficientes, de modo que o baixo desenvolvimento econômico de determinado país pode ser explicado pela persistência de um quadro institucional que gera a ineficiência. Não se descuida que alterações institucionais podem contribuir para a alteração desse panorama, sendo certo que é muito mais fácil alterar as instituições formais do que as informais. Alterações nas instituições formais podem repercutir nas instituições informais, o que nem sempre ocorre (NORTH, 1990, p. 27), na medida em que estas decorrem de valores culturais e de práticas coletivas constantemente repetidas ao longo do tempo, capazes, inclusive, de sobreviver a guerras ou revoluções (NORTH, 1990, p. 37). Nesse sentido, a interessante reflexão de Becker (2007, p. 65):

Suponhamos, como Everett Hughes gostaria de sugerir, que uma grande revolução fosse acontecer amanhã, uma revolução semelhante em alcance e magnitude àquelas que os cientistas sociais mais gostariam de estudar, como as Revoluções Francesa ou Chinesa. O que mudaria e o que continuaria igual? Os jornais poderiam ficar diferentes, os programas de televisão quase certamente ficariam diferentes. O sistema de coleta de lixo mudaria? Talvez. O sistema de distribuição de água mudaria? Quase certamente não. (...) o exercício pode nos fazer compreender que, muito provavelmente, nem tudo mudaria. Muitas coisas tenderiam a acontecer tal como antes.

Conforme preconiza Douglas North, a matriz institucional é permeada por um rol interdependente de restrições formais e informais que determinam o desempenho econômico. Mudanças específicas no quadro institucional formal ou informal não revertem necessariamente os caminhos de sucesso ou fracasso, pois uma mudança econômica de longo prazo é a consequência de inúmeras decisões marginais de curto prazo tomadas por empreendedores políticos e econômicos, que, indiretamente, moldam o desempenho de um país (NORTH, 1990, p. 100-104).

North consagra, portanto, a percepção de que as relações econômicas se operam num determinado ambiente, no qual agem instituições formais e informais que as vezes se compatibilizam com esforços no sentido da busca da eficiência, as vezes representam uma barreira a esse objetivo. Uma mudança institucional isolada, por outro lado, pode não favorecer objetivos universais.

\footnotetext{
${ }^{6}$ Conforme ensina Marcia Carla Ribeiro, no escólio do pensamento de Herbert A. Simon, a racionalidade limitada não se restringe à limitação informacional por parte do agente, mas abarca também a incapacidade de processamento da informação disponível. (RIBEIRO, 2011, p. 66.).
} 
Feitas essas ponderações passa-se a abordar, dentro das limitações desse trabalho, o papel desempenhado pelas instituições informais e formais na eficiência do Poder Judiciário.

\section{A INFLUÊNCIA DAS INSTITUIÇÕES INFORMAIS NA EFICIÊNCIA DO PODER JUDICIÁRIO}

Os estudos de Chase (2014, p. 21) demonstram que os processos de resolução de litígios em muito são influenciados pelo contexto cultural em que se inserem. É impossível compreendê-los exclusivamente como produtos da técnica e do conhecimento científico dos técnicos que operam o direito.

As instituições de resolução de conflitos condicionam e são condicionadas pela cultura, assim compreendida como as crenças, os ideais, as normas e as tradições de um povo (BOBBIO, 1998, p. 306).

$\mathrm{Na}$ análise do contexto brasileiro, é importante levar em conta a grande influência que o patriarcalismo exerceu em nossa formação história, de modo que, na lição de Sérgio Buarque de Holanda, os profissionais formados em tal ambiente eram incapazes de distinguir nitidamente o espaço público do espaço privado. Diferente do burocrata pensado por Max Weber, o funcionário patrimonial brasileiro utiliza-se da função pública para a obtenção de benefícios de ordem particular. Mesmo a seleção dos ocupantes dos cargos públicos historicamente fez-se segundo laços perpassados pela confiança pessoal. Nas palavras de Buarque de Holanda (2013, p. 146):

Falta a tudo a ordenação impessoal que caracteriza a vida no Estado burocrático. $\mathrm{O}$ funcionalismo patrimonial pode, com a progressiva divisão das funções e com a racionalização, adquirir traços burocráticos. Mas, em sua essência ele é tanto mais diferente do burocrático, quanto mais caracterizados estejam os dois tipos. No Brasil, pode-se dizer que só excepcionalmente tivemos um sistema administrativo e um corpo de funcionários puramente dedicados a interesses objetivos e fundados nesses interesses. Ao contrário, é possível acompanhar, ao longo da nossa história, o predomínio constante das vontades particulares que encontram seu ambiente próprio em círculos fechados e pouco acessíveis a uma ordenação impessoal.

Na opinião de Marinoni (2014, p. 85-86), esses fatores influenciaram e influenciam a administração da justiça, notadamente com a formação de grupos nos tribunais e a existência de decisões favoráveis a advogados que deixam de ser simples defensores dos interesses de seus clientes, para transformarem-se em bajuladores e lobistas.

De toda sorte, tais instituições informais - que conduzem à ineficiência - devem ser levadas em conta em um estudo que busque entender as causas globais que ensejam a ineficiência do Poder Judiciário brasileiro. Outrossim, não se descuida que a eliminação de tais práticas, que há muito tempo estão arraigadas em nosso contexto, não se dará da noite para o dia. 
Mas a influência das instituições informais não se esgota nos aspectos previamente expostos, de modo que é impossível enumerar todos os seus desdobramentos. Para além da ética que deve conduzir aqueles que movimentam a máquina judiciária - advogados, juízes, promotores, servidores etc. - faz-se necessária a presença de sólida formação técnica, pois, mesmo que haja leis eficientes e estrutura de trabalho adequada, o sistema não funcionará de forma eficiente caso não existam profissionais capazes de lidar com tal aparato. Aqui pode ser aplicada a metáfora elaborada por Douglas North, pela qual, ainda que as regras do jogo sejam as mesmas, há claras diferenças na dinâmica de esportes competitivos quando praticados por amadores ou por profissionais (NORTH, 1990, p. 74).

Mesmo a forma pela qual o judiciário é utilizado decorre de circunstâncias culturais, de modo que grande parcela da morosidade é fomentada pelo uso predatório desse serviço por litigantes habituais - como as instituições financeiras, as empresas de telefonia e o próprio Poder Público.

Some-se a isso o fato de que no Brasil, diferentemente do que ocorre em outros países, não há uma cultura disseminada de utilização de meios alternativos de solução de litígios (como a arbitragem) ou mesmo a cultura do acordo. Este último, capaz de contribuir para o descongestionamento da justiça, é exemplo de instituição informal que pode ser fomentada e aprimorada por meio de instituições formais, notadamente por campanhas, ou mesmo leis, que incentivem tais condutadas.

Além desses exemplos, é plausível cogitar que eventual dificuldade de aplicação ao Poder Judiciário de práticas próprias à administração gerencial, cuja implementação no Brasil consagrou-se com a promulgação da EC 19/98, decorra de fatores culturais e de instituições informais correlacionadas ao corporativismo que historicamente acompanhou a prestação jurisdicional no país.

Pois bem. Superada essa temática, a seguir será tratado da relação entre as instituições formais e a eficiência do Poder Judiciário.

\section{A INFLUENCIA DAS INSTITUIÇÕES FORMAIS NA EFICIÊNCIA DO PODER JUDICIÁRIO}

A relação entre as instituições formais e eficiência do Poder Judiciário pode ser correlacionada com a qualidade das leis, especialmente as de natureza processual, em função da natureza do serviço em questão.

No estudo do tema, o primeiro fator que deve ser considerado é que as leis processuais são feitas em um contexto de assimetria informacional. Nos dizeres de Vicente de Paula Ataíde Junior, os esquemas lógicos pelos quais são pensadas as leis processuais são incapazes de dar conta das necessidades do direito material, e da realidade vivenciada nos órgãos jurisdicionais (ATAÍDE JUNIOR, 2013, p. 32). Para Ataíde Junior (2013, p. 33): 
Mesmo que influenciados pelo instrumentalismo, os trabalhos científicos do direito processual civil continuam partindo dos textos legais para conhecer o fenômeno jurídico, sem buscar apoio em dados empíricos para mensurar a adequação de suas propostas à realidade. Mesmo que recorrendo ao texto constitucional, essa postura não muda: as soluções para os problemas processuais continuam a partir do pensamento e das elucubrações teóricas, como verdadeiros exercícios de lógica jurídica, sem qualquer aporte da metodologia própria das ciências sociais.

O trecho transcrito demostra que a doutrina responsável pela construção das normas processuais furtase em realizar pesquisas de campo e a trabalhar com dados estáticos, o que empobrece a eficiência das leis.

Nesses termos, partindo-se da premissa de que leis processuais eficientes podem contribuir, ainda que parcialmente, para a resolução da morosidade do Poder Judiciário, é de se cogitar que os responsáveis por sua elaboração passem a trabalhar com dados concretos, aptos a reduzir a assimetria informacional que perpassa a elaboração legislativa.

Infelizmente, não parece ter sido esse o norte dos trabalhos que orientaram a elaboração do Novo Código de Processo Civil (Lei n. ${ }^{0}$ 13.105, de 16 de março de 2015), que foram pautados pelos métodos tradicionais, embebecidos pelo paradigma racionalista, que há séculos permeia a dogmática jurídica.

Não se descuida que a realização de estudos que trabalhem com dados estatísticos, e que voltem os olhos às situações que diuturnamente surgem na prática do operador do direito, demandará maiores esforços do doutrinador, o qual, muitas vezes, faz da pesquisa uma atividade secundária, realizada em suas horas de folga. Porém, uma nova postura faz-se necessária.

Outro tema importante que deve ser considerado diz com a importação de leis cunhadas em contextos alienígenas.

Segundo Sacco (2001, p. 42-43), a importação de modelos estrangeiros pode ocorrer por duas maneiras: pela recepção global de um modelo alienígena (tal como ocorreu com a propagação dos modelos franceses após 1806), ou pela seleção de soluções pontuais. Ainda conforme Sacco (2001, p. 42-43), a importação, quando conjugada com um sólido modelo de comparação, é capaz de acelerar o desenvolvimento do direito.

Abordando o fenômeno sob outra ótica, Virgílio Afonso da Silva constata que há um certo deslumbramento pelos juristas brasileiros em relação àquilo que é feito em outros países ("doutrina mais moderna"), especialmente em relação à Alemanha, o que levou o citado autor a cunhar o seguinte brocardo: "o que é bom para Alemanha, é bom para o Brasil” (SILVA, 2006, p. 199-200).

Registre-se que tal circunstância foi alvo das atenções de Douglas North. O economista relatou o insucesso dos países do Terceiro Mundo que importaram sem maiores adaptações modelos legislativos bem sucedidos nos Estados Unidos. Conforme North, ainda que as regras fossem as mesmas, a formas de efetivação, bem como aspectos culturais ligados às instituições informais, tais como as normas de comportamento e os modelos subjetivos dos atores, divergiam (NORTH, 1991, p. 101). 
Disso se extrai que a efetividade das instituições formais (entre as quais se inserem as leis) também depende da adaptabilidade delas ao quadro institucional informal existente em determinado país.

\section{CONCLUSÕES}

O Poder Judiciário brasileiro está em crise. A taxa de congestionamento permanece elevada e as metas impostas pelo $\mathrm{CNJ}$ preocupadas essencialmente com aspectos quantitativos, o que as conduz a muitas vezes se afastarem de critérios qualitativos de avaliação dos serviços prestados e acabam por prejudicar magistrados, servidores e administrados em razão da sobrecarga de trabalho que lhes é imposta.

O excessivo volume de demandas em trâmite tem como causas aparentes a inafastabilidade da prestação jurisdicional (erigida à garantia fundamental pela Constituição de 1998), o acesso gratuito à Justiça, a presença de litigantes habituais que enriquecem com a morosidade e utilizam do serviço jurisdicional de forma predatória etc.

Por outro lado, entende-se que o serviço jurisdicional deve ser visto como um serviço público, cuja prestação o Estado reservou para si em função de sua natureza e importância. Sendo um serviço público, exsurge o dever constitucional de prestação com eficiência (que deve ser entendida como a busca dos melhores resultados com o menor dispêndio possível de recursos).

Nesta toada, o Novo Código de Processo Civil aparece com a promessa de dar eficiência à prestação judicial. Todavia, a simples declaração retórica não é suficiente. Conforme ensina Remo Caponi, a eficiência do Poder Judiciário deve ser compreendida com base nos fatores legislativos, estruturais e culturais.

A modificação de prazos e até mesmo a eliminação de recursos não parece sustentar uma proposta de aperfeiçoamento do sistema suficiente a que as suas principais vicissitudes sejam corrigidas. O esforço para tal objetivo poderia incorporar conceitos propostos pela Nova Economia Institucional, de forma a ampliar o foco de visão ao admitir que reformas institucionais formais podem não ser suficientes ao aprimoramento pretendido, já que cultura e a dependência histórica impactam na eficiência.

Eventuais alterações legislativas podem, de alguma maneira, reduzir a ineficiência, mas a questão deve ser entendida de uma forma mais ampla, razão pela qual mostra-se útil a abordagem institucional da forma como elaborada pelo economista Douglas North.

Para North, as instituições são as regras do jogo da vida em sociedade, e possuem a função de reduzir a incerteza, ainda que não necessariamente o façam de forma eficiente pois a cultura prevalente pode ser eivada de vícios que interfiram nos resultados planejados.

Já as organizações também exercem a função de redução da incerteza, mas aparecem em um momento posterior - são criadas com base nas oportunidades possibilitadas pelo quadro institucional existente e depois de criadas sofrem a influência das instituições ao mesmo tempo em que as podem influenciar. 
As instituições podem ser formais e informais. As primeiras correspondem às regras oficiais, podendo, na maioria dos casos estar associadas a uma vontade estatal. Já as informais relacionam-se às regras não escritas enraizadas nas interações sociais e ligadas a fatores culturais. O processo de alteração das instituições informais é mais difícil e demorado.

$\mathrm{O}$ artigo procura alertar para a possibilidade de tais conceitos serem associados ao objetivos de aprimoramento da eficiência do Poder Judiciário de diversas maneiras. Em uma primeira abordagem, pode-se considerar que as formas de solução de litígios não decorrem apenas de aspectos meramente técnicos, mas são perpassadas por dados de ordem cultural. Em outra toada, nota-se que o histórico patriarcalismo brasileiro (instituição informal por essência), simbolizado pelo uso privado do espaço público, ainda está longe de ser totalmente extirpado, sendo, portanto, um dado a ser considerado em um estudo que busque aferir as causas globais que levam à ineficiência do nosso sistema judicante. Por outro lado, é plausível cogitar que instituições informais também se manifestam na resistência à implementação de uma administração gerencial no Poder Judiciário, na cultura da litigiosidade, na resistência aos meios alternativos de solução e na baixa percentagem de acordos.

Sobre as instituições formais e a eficiência do serviço jurisdicional, tem-se que elas não são, por si só capazes de reverter um quadro de ineficiência, todavia, podem dar uma contribuição - ainda que marginal.

Nesse aspecto, dada a natureza do serviço em análise, as leis processuais assumem notória importância. Contudo, tradicionalmente têm sido elaboradas em um contexto de absoluta assimetria informacional, de modo que os doutrinadores ainda estão, via de regra, presos a um superado paradigma racionalista, que trabalha apenas com esquemas lógicos e abstratos. A adoção de novas metodologias e a utilização de dados concretos pode clarificar e otimizar a elaboração das leis.

Ainda nesse aspecto, é possível criticar a importação, sem adaptações, de soluções legislativas que tiveram sucesso em outros contextos, isso porque a funcionalidade de determinado esquema legal é dependente da adaptabilidade ao quadro institucional informal vigente.

Constata-se que a superação da ineficiência do Poder Judiciário somente ocorrerá no longo prazo, após reiteradas soluções marginais tomadas em contextos institucionais e formais, que dependerão da atuação dos agentes políticos e econômicos envolvidos.

Além da compreensão global do contexto e do uso dados estatísticos, as ações destinadas à mudança devem ser norteadas por uma intensa análise dos fatores culturais envolvidos, de modo que sejam pensadas soluções passíveis de assimilação no âmbito informal, para, em um segundo momento, gradualmente alterá-lo por meio de intervenções pontuais. 


\title{
AN ANALYSIS OF JUDICIAL EFFICIENCY BASED ON THINKING OF DOUGLAS NORTH
}

\begin{abstract}
This study seeks to question the judiciary efficiency, designed as a public service. Therefore, it is considered that only legislative changes will not be enough to reverse the inefficiency of context, because the scenery is wider, and cultural factors should be considered, which shows the importance of institutional analysis promoted by Douglas North. Using bibliographic research and secondary data, the Article considers the framework of the proposed issue to conclude that the efficiency of the dispute settlement system does not depend solely on the reform of civil procedural law.
\end{abstract}

Keywords: Efficiency ; Judiciary; Douglass North ; Institutions; Culture.

\section{REFERENCIAS}

AGUSTINHO, Eduardo Oliveira; RIBEIRO, Márcia Carla. "Economia Institucional e Nova Economia Institucional”. In: Marcia Carla Ribeiro e Vinicius Klein. (Org.). O que é análise Econômica do Direito: uma introdução. Belo Horizonte: Editora Forum, 2011.

ARENHART, Sérgio Cruz. A tutela coletiva de interesses individuais: para além da proteção dos interesses individuais homogêneos. São Paulo: Revista dos Tribunais, 2013.

ATAÍDE JUNIOR, Vicente, 2013. Processo civil pragmático. Tese de Doutoramento, Programa de PósGraduação em Direito, Universidade Federal do Paraná, PR.

BECKER, Howard S. Segredos e truques da pesquisa. Rio de Janeiro: Zanhar, 2007.

BITTENCOURT, Maurício Vaz Lobo. "Princípio da eficiência”. In: RIBEIRO, Márcia Carla Pereira; KLEIN, Vinícius (org.). O que é análise econômica do direito: uma introdução. Belo Horizonte: Fórum, 2011.

BOBBIO, Norberto; MATTEUCCI, Nicola; PASQUINO, Gianfranco. Dicionário de política. 11.a ed. Brasília: Editora UNB, 1998.

BUARQUE DE HOLANDA, Sérgio. Rázes de Brasil. 26. ed. São Paulo: Companhia das Letras, 2013.

CAPONI, Remo. O princípio da proporcionalidade na justiça civil: primeiras notas sistemáticas. Revista de Processo. v. 192, 2011.

CARVALHO FILHO, José dos Santos. Manual de direito administrativo. 27. a ed. São Paulo: Atlas, 2014.

CHASE, Oscar G. Direito, cultura e ritual: sistemas de resolução de conflitos no contexto da cultura comparada. São Paulo: Marcial Pons, 2014.

COMISSÃO DE JURISTAS NOVO CPC. Relatório sobre os resultados da primeira fase dos trabalhos. Brasília: Senado Federal, 2009. Disponível em: <http://www.oab.org.br/pdf/CartilhalaFase.pdf>. Acesso em: 20 dez. 
2014.

CONSELHO NACIONAL DE JUSTIÇA. Justiça em números 2014: ano-base 2013. Brasília: CNJ, 2014. Disponível em: <ftp://ftp.cni.jus.br/Justica_em_Numeros/relatorio_jn2014.pdf $>$. Acesso em: 20 dez. 2014.

DJANKOV, Simeon; LA PORTA, Rafael; LOPEZ-DE-SILANES, Florencio; SHLEIFER, Andrei. Court. Washington: World $2002 . \quad$ Bank, Disponível <http://www.doingbusiness.org/ /media/FPDKM/Doing\%20Business/Documents/Methodology/Supporti ng-Papers/DB-Methodology-Courts.pdf>. Acesso em: 18 dez. 2014.

GICO JUNIOR, Ivo Teixeira, 2012. A Tragédia do Judiciário: subinvestimento em capital jurídico e sobreutilização do Judiciário. Tese de Doutoramento, publicação 002/2012, Departamento de Economia, Programa de Pós-Graduação em Economia, Universidade de Brasília, DF.

GROSSI, Paolo. História da propriedade e outros ensaios. Rio de Janeiro: Renovar, 2006.

MARINONI, Luiz Guilherme. A ética dos procedentes: justificativa do novo CPC. São Paulo: Revista dos Tribunais, 2014.

NORTH, Douglas C. Institutions, institutional change and economic performance. Cambridge: Cambridge University Press, 1990.

ORLANDI, Eni Puccineli. Análise de discurso: princípios e procedimentos. Campinas: Pontes, 2000.

RIBEIRO, Márcia Carla. "Racionalidade limitada". In: Marcia Carla Ribeiro e Vinicius Klein. (Org.). O que é análise Econômica do Direito: uma introdução. Belo Horizonte: Editora Forum, 2011.

ROPPO, Enzo. O contrato. Coimbra: Edições ALMEDINA S.A., 2009.

SACCO, Rodolfo. Introdução ao Direito Comparado. São Paulo: Revista dos Tribunais, 2001.

SILVA, Virgílio Afonso da. Interpretação conforma a constituição: entre a trivialidade e a centralização judicial. Revista de Direito GV,v. 3, p. 191-210, 2006.

TOKARS, Fabio Leandro. “Assimetria informacional”. In: Marcia Carla Ribeiro e Vinicius Klein. (Org.). O que é análise Econômica do Direito: uma introdução. Belo Horizonte: Editora Forum, 2011.

Trabalho enviado em 04 de maio de 2016.

Aceito em 20 de julho de 2016. 